\title{
Distribution of Salmonella serovars along the food chain in Poland, 2010-2015
}

\author{
Magdalena Skarżyńska, Andrzej Hoszowski, Magdalena Zając, \\ Anna Lalak, Ilona Samcik, Renata Kwit, Dariusz Wasyl \\ Department of Microbiology \\ National Veterinary Research Institute, 24-100 Pulawy, Poland \\ magdalena.skarzynska@piwet.pulawy.pl \\ Received: January 24, 2017 \\ Accepted: May 10, 2017
}

\begin{abstract}
Introduction: Data collection on the Salmonella occurrence is crucial in effective implementation of different actions or control programmes aiming to protect consumers' health and to reduce the level of Salmonella prevalence in farm animals. The goal was to describe Salmonella serovar distribution along the food chain in Poland during 2010-2015 and to identify their epidemiological importance. Material and Methods: Slide agglutination according to White-Kauffmann-Le Minor scheme was used to identify Salmonella serovars of 6,928 isolates originating from animals, food, feeds, and fertilisers. Results: In total, 160 Salmonella serovars were identified. Differences in serovar distribution were observed depending on animal species. Among isolates from hens, $S$. Enteritidis and $S$. Infantis were the most prevalent. Serovar pattern in turkeys differed from those in hens, with $S$. Kentucky, $S$. Newport, $S$. Saintpaul being the most prevalent. Monophasic $S$. Typhimurium was predominant in pigs. Serovars found in food reflected those observed among livestock animals. Nine out of the ten most prevalent serovars in animals and humans were also found in organic fertilisers. Conclusion: Serotyping of large number of isolates from different sources is essential for insight on emerging serovars and trends of Salmonella occurrence. This may increase the value of epidemiological data and result in updating of Salmonella control programmes to target further epidemiologically important serovars in animals and better protection of consumers' health.
\end{abstract}

Keywords: Salmonella serovars, salmonellosis, food chain, Poland.

\section{Introduction}

Salmonella infections, despite years of eradication, still constitute an important epidemiological and economic problem worldwide. According to data presented by the European Food Safety Authority (EFSA) in 2015, 94,625 cases of Salmonella infections were confirmed in humans, including 126 fatal, making salmonellosis the second most commonly reported zoonosis across the European Union. This was a $1.9 \%$ increase compared with $2014(10,11)$. Salmonella Enteritidis still remains the most prevalent serovar responsible for human salmonellosis, but epidemiological importance of other Salmonella serovars like monophasic $S$. Typhimurium 1,4,[5],12:i:- and $S$. Infantis increased during the study period $(10,11)$. In the USA salmonellosis was the most frequent bacterial foodborne illness in 2014 with 140 outbreaks out of 247 bacterial outbreaks noted $(56.6 \%)$ and 2,395 cases constituting $27 \%$ of all illnesses (6).
Salmonella serovars differ in their ability to cause infections in humans $(12,23)$. Although a limited number of over 2,600 Salmonella serovars are of public health importance, all of them are potentially harmful and have a zoonotic potential $(15,31)$. It is worth pointing out that not only multidrug-resistant strains are responsible for human illnesses (4).

Contaminated food of animal origin is the main source of Salmonella for humans. Transmission of the pathogen to consumers is most often related to consumption of poultry products. Animals, often being asymptomatic pathogen carriers, are of particular importance in the spread of Salmonella. Travel and international trade also contribute to global increase of Salmonella-related risk (31). Information on the distribution of Salmonella serovars in food, feedingstuffs, animals and their environment is important to identify the sources and pathways of infections and can give insight into contamination routes. The ultimate aim of Salmonella control in 
husbandry is to decrease pathogen prevalence along animal production chain and to reduce public health consequences of its spread to humans.

Our goal was to describe the distribution of Salmonella serovars along the food chain in Poland between 2010 and 2015 and to identify their importance to the epidemiology of human and animal salmonellosis.

\section{Material and Methods}

Between 2010 and 2015 a total of 10,422 Salmonella isolates were tested in the National Reference Laboratory for Salmonellosis (NRL) at the National Veterinary Research Institute (NVRI). Salmonella strains were either submitted to NRL by regional veterinary laboratories for confirmatory testing or isolated at the NVRI. The isolates were obtained under national Salmonella control programmes in poultry, official controls for compliance with feed and food law, research projects conducted at the NVRI, and routine commercial services. Duplicates and isolates without sufficient data on source of isolation were excluded and finally 6,928 strains were serotyped. They originated from food-producing animals and their environment, food of animal origin, feedingstuffs, and other sources, including fertilisers (Fig. 1).

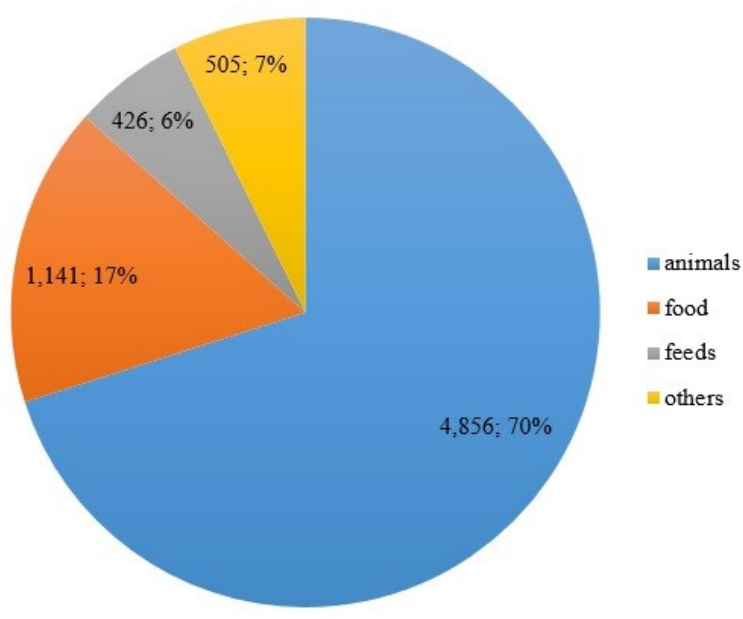

Fig. 1. The origin of tested Salmonella strains

Salmonella detection was carried out in the country-wide network of official veterinary diagnostic laboratories according to procedures compliant with PN-EN ISO 6579:2003 standard (26). Serotyping was performed by slide agglutination method according to White-Kauffmann-Le Minor scheme (15), using commercial sera manufactured by: Immunolab (Poland), Biomed (Poland), Sifin (Germany), Statens Serum Institut (Denmark), and Mast Group (U.K.). Monophasic S. Typhimurium strains (1,4,[5],12:i:-) were confirmed with PCR method recommended by the EFSA $(16,33)$. The variability of serovars observed in various sources was measured with Simpson's diversity index (21).
Table 1. Sample types and number of Salmonella isolates from food, animals, and feedingstuffs

\begin{tabular}{|c|c|}
\hline $\begin{array}{c}\text { Food } \\
(\mathrm{n}=1,141)\end{array}$ & \multirow{2}{*}{$\%$ (numbers) } \\
\hline Sample type & \\
\hline broiler meat & $42.2 \%(482)$ \\
\hline samples from food processing plant & $15.3 \%(175)$ \\
\hline $\begin{array}{l}\text { poultry meat and poultry meat products } \\
\text { (unspecified) }\end{array}$ & $15.3 \%(175)$ \\
\hline pork and pork products & $12.3 \%(140)$ \\
\hline turkey meat & $8.6 \%(98)$ \\
\hline meat (other, mixed, unspecified) & $2.9 \%(33)$ \\
\hline beef and beef products & $2.3 \%(26)$ \\
\hline others and unspecified & $1.1 \%(12)$ \\
\hline \multicolumn{2}{|l|}{$\begin{array}{c}\text { Animals } \\
(\mathrm{n}=4,856)\end{array}$} \\
\hline \multicolumn{2}{|l|}{ Sample type } \\
\hline livestock environment (farm) & $\begin{array}{l}55.5 \% \\
(2697) \\
\end{array}$ \\
\hline secretions / excretions (faeces) & $\begin{array}{l}31.1 \% \\
(1511) \\
\end{array}$ \\
\hline internal organs and tissues & $6.9 \%(335)$ \\
\hline transportation environment & $1.4 \%(70)$ \\
\hline swabs / washes / scrapings & $0.5 \%(25)$ \\
\hline poultry hatching facility & $0.4 \%(17)$ \\
\hline others and unspecified & $4.1 \%(201)$ \\
\hline \multicolumn{2}{|l|}{$\begin{array}{c}\text { Feedingstuffs } \\
(\mathrm{n}=426)\end{array}$} \\
\hline \multicolumn{2}{|l|}{ Sample type } \\
\hline feed production plant environment & $22.8 \%(97)$ \\
\hline plant feed materials & $21.4 \%(91)$ \\
\hline animal feed materials & $14.1 \%(60)$ \\
\hline pet feed & $13.4 \%(57)$ \\
\hline compound feed for poultry & $8.9 \%(38)$ \\
\hline compound feed for swine & $4.2 \%(18)$ \\
\hline compound feed for ruminants & $4.0 \%(17)$ \\
\hline others and unspecified & $11.3 \%(48)$ \\
\hline
\end{tabular}

\section{Results}

Among 6,928 isolates, 160 Salmonella serovars were identified as follows: 124 in animals, 44 in food, 73 in animal feeds, and 15 in fertilisers. The majority of serovars $(\mathrm{n}=146)$ were rarely (less than 53 isolates) noted during the study (data not shown).

Differences in Salmonella serovars distribution were observed depending on animal species (Table 2).

Among 3,191 isolates from hens 52 Salmonella serovars were identified. $S$. Enteritidis was the most prevalent $(54,7 \%)$. High contributions of $S$. Infantis $(14.0 \%)$ and $S$. Mbandaka (8.4\%) were noted. $S$. Typhimurium, $S$. Virchow, $S$. Newport, and rough strains were also reported among the top serovars in hens $(3.5 \%, 3.2 \%, 2.6 \%$, and $2.4 \%$, respectively). Other serovars were involved in $11.1 \%$ of total cases. Similar serovar distribution was observed in broilers, laying hens, and breeding flocks of Gallus gallus (data not presented). Simpson's diversity ratio calculated for hen isolates was the lowest amongst analysed sources and it was undoubtedly connected with limited number of predominant serovars $(\mathrm{D}=0.670$, Table 2$)$. 
Table 2. Diversity of Salmonella serovars found in animals and their environment, in food of animal origin, animal feedingstuffs, and fertilisers

\begin{tabular}{|c|c|c|c|c|c|c|c|}
\hline $\begin{array}{c}\text { Source } \\
\text { and serovar }\end{array}$ & \multirow{2}{*}{$\%$ (numbers) } & $\begin{array}{c}\text { Source } \\
\text { and serovar }\end{array}$ & \multirow{2}{*}{$\%$ (numbers) } & $\begin{array}{c}\text { Source } \\
\text { and serovar }\end{array}$ & \multirow{2}{*}{$\%$ (numbers) } & $\begin{array}{c}\text { Source } \\
\text { and serovar }\end{array}$ & \multirow{2}{*}{$\%$ (numbers) } \\
\hline $\begin{array}{c}\text { hens } \\
(\mathrm{n}=3,191 \\
\mathrm{D}=0.670)\end{array}$ & & $\begin{array}{c}\text { turkeys } \\
(\mathrm{n}=486 ; \\
\mathrm{D}=0.887)\end{array}$ & & $\begin{array}{c}\text { geese } \\
(\mathrm{n}=381 ; \\
\mathrm{D}=0.736)\end{array}$ & & $\begin{array}{c}\text { ducks } \\
(\mathrm{n}=226 \\
\mathrm{D}=0.772)\end{array}$ & \\
\hline Enteritidis $^{\mathrm{H}}$ & $54.7(1744)$ & Kentucky $^{\mathrm{H}}$ & $22.4(109)$ & Typhimurium $^{\mathrm{H}}$ & $38.1(145)$ & Enteritidis $^{\mathrm{H}}$ & $42.9(97)$ \\
\hline Infantis $^{\mathrm{H}}$ & $14.0(447)$ & Newport $^{\mathrm{H}}$ & $16.0(78)$ & Enteritidis $^{\mathrm{H}}$ & $33.1(126)$ & Typhimurium $^{\mathrm{H}}$ & $17.7(40)$ \\
\hline Mbandaka $^{\mathrm{H}}$ & $8.4(269)$ & Saintpaul ${ }^{\mathrm{H}}$ & $13.2(64)$ & Newport ${ }^{\mathrm{H}}$ & $6.6(25)$ & Indiana $^{\mathrm{H}}$ & $8.4(19)$ \\
\hline Typhimurium $^{\mathrm{H}}$ & $3.5(113)$ & Typhimurium $^{\mathrm{H}}$ & $9.1(44)$ & Indiana $^{\mathrm{H}}$ & $6.3(24)$ & Newport $^{\mathrm{H}}$ & $5.3(12)$ \\
\hline Virchow $^{\mathrm{H}}$ & $3.2(102)$ & Enteritidis $^{\mathrm{H}}$ & $7.2(35)$ & Mbandaka $^{\mathrm{H}}$ & $5.0(19)$ & S. sp. (rough) & $4.0(9)$ \\
\hline Newport $^{\mathrm{H}}$ & $2.6(83)$ & Lexington & $5.8(28)$ & Hadar $^{\mathrm{H}}$ & $1.3(5)$ & Give & $3.5(8)$ \\
\hline S. sp. (rough) & $2.4(78)$ & Stanley ${ }^{\mathrm{H}}$ & $3.5(17)$ & Kottbus & $1.0(4)$ & Kottbus & $3.5(8)$ \\
\hline Senftenberg & $1.9(60)$ & Agona $^{\mathrm{H}}$ & $3.1(15)$ & $\underline{1}, 4,[5], 12: \mathrm{i}^{\mathrm{H}} \mathrm{H}^{\mathrm{H}}$ & $1.0(4)$ & Anatum & $2.7(6)$ \\
\hline Indiana $^{\mathrm{H}}$ & $1.6(50)$ & Anatum & $2.5(12)$ & Agona $^{\mathrm{H}}$ & $0.8(3)$ & Infantis $^{\mathrm{H}}$ & $1.8(4)$ \\
\hline Hadar $^{\mathrm{H}}$ & $0.7(23)$ & $\underline{1}, 4,[5], 12: \mathrm{i}^{-{ }^{\mathrm{H}}}$ & $1.9(9)$ & Infantis $^{\mathrm{H}}$ & $0.8(3)$ & Saintpaul & $1.8(4)$ \\
\hline Tennessee & $0.6(19)$ & Mbandaka & $1.6(8)$ & Virchow $^{\mathrm{H}}$ & $0.8(3)$ & Senftenberg & $1.3(3)$ \\
\hline Agona $^{\mathrm{H}}$ & $0.5(17)$ & Bredeney & $1.4(7)$ & Anatum & $0.5(2)$ & Hadar $^{\mathrm{H}}$ & $0.9(2)$ \\
\hline Kottbus & $0.5(17)$ & Indiana & $1.4(7)$ & Oranienburg & $0.5(2)$ & London & $0.9(2)$ \\
\hline Braenderup $^{\mathrm{H}}$ & $0.4(14)$ & Infantis ${ }^{\mathrm{H}}$ & $1.2(6)$ & Schleissheim $^{\mathrm{H}}$ & $0.5(2)$ & Tennessee & $0.9(2)$ \\
\hline Coeln & $0.4(14)$ & Virchow & $1.2(6)$ & S. sp. (rough) & $0.5(2)$ & $\underline{1}, 4,[5], 12: \mathrm{i}^{-}{ }^{\mathrm{H}}$ & $0.4(1)$ \\
\hline other & $4.4(141)$ & other & $8.4(41)$ & other & $3.1(12)$ & other & $4.0(9)$ \\
\hline $\begin{array}{c}\text { Source } \\
\text { and serovar }\end{array}$ & \multirow[b]{2}{*}{$\%$ (numbers) } & $\begin{array}{c}\text { Source } \\
\text { and serovar }\end{array}$ & \multirow[b]{2}{*}{$\%$ (numbers) } & $\begin{array}{c}\text { Source } \\
\text { and serovar }\end{array}$ & \multirow[b]{2}{*}{$\%$ (numbers) } & $\begin{array}{c}\text { Source } \\
\text { and serovar }\end{array}$ & \multirow[b]{2}{*}{$\%$ numbers } \\
\hline $\begin{array}{c}\text { swine } \\
(\mathrm{n}=224 ; \\
\mathrm{D}=0.724)\end{array}$ & & $\begin{array}{c}\text { food } \\
(\mathrm{n}=1,141 ; \\
\mathrm{D}=0.881)\end{array}$ & & $\begin{array}{c}\text { feedingstuffs } \\
\quad(n=426 ; \\
D=0.954)\end{array}$ & & $\begin{array}{c}\text { fertilisers } \\
(\mathrm{n}=31 \\
\mathrm{D}=0.912)\end{array}$ & \\
\hline$\underline{1}, 4,[5], 12:{\mathrm{i}:-{ }^{\mathrm{H}}}^{-}$ & $47.8(107)$ & Infantis $^{\mathrm{H}}$ & $23.4(267)$ & Mbandaka $^{\mathrm{H}}$ & $10.8(46)$ & Infantis $^{\mathrm{H}}$ & 7 \\
\hline Derby ${ }^{\mathrm{H}}$ & $19.6(44)$ & Enteritidis $^{\mathrm{H}}$ & $17.6(201)$ & Infantis $^{\mathrm{H}}$ & $8.9(38)$ & Virchow $^{\mathrm{H}}$ & 5 \\
\hline Typhimurium $^{\mathrm{H}}$ & $8.9(20)$ & Indiana $^{\mathrm{H}}$ & $10.8(123)$ & Agona $^{\mathrm{H}}$ & $8.0(34)$ & Enteritidis ${ }^{\mathrm{H}}$ & 4 \\
\hline Infantis $^{\mathrm{H}}$ & $4.5(10)$ & Newport $^{\mathrm{H}}$ & $9.8(112)$ & Derby $^{\mathrm{H}}$ & $6.6(28)$ & Schleissheim $^{\mathrm{H}}$ & 3 \\
\hline Choleraesuis & $2.7(6)$ & Typhimurium $^{\mathrm{H}}$ & $7.2(82)$ & Senftenberg & $6.1(26)$ & Newport $^{\mathrm{H}}$ & 2 \\
\hline Enteritidis $^{\mathrm{H}}$ & $2.2(5)$ & Kentucky ${ }^{\mathrm{H}}$ & $4.8(55)$ & Enteritidis $^{\mathrm{H}}$ & $5.2(22)$ & $\underline{1}, 4,[5], 12: \mathrm{i}^{-}{ }^{\mathrm{H}}$ & 1 \\
\hline Rissen & $2.2(5)$ & Saintpaul ${ }^{\mathrm{H}}$ & $3.0(34)$ & Typhimurium $^{\mathrm{H}}$ & $4.5(19)$ & Bredeney & 1 \\
\hline S sp. (rough) & $1.8(4)$ & Virchow $^{\mathrm{H}}$ & $2.8(32)$ & Lexington & $3.8(16)$ & Derby ${ }^{\mathrm{H}}$ & 1 \\
\hline $6,7:-: 1,5$ & $0.9(2)$ & Derby $^{\mathrm{H}}$ & $2.7(31)$ & Livingstone & $3.3(14)$ & Kentucky $^{\mathrm{H}}$ & 1 \\
\hline Agona $^{\mathrm{H}}$ & $0.9(2)$ & Mbandaka $^{\mathrm{H}}$ & $2.6(30)$ & 4:d:- & $2.1(9)$ & London & 1 \\
\hline Brandenburg $^{\mathrm{H}}$ & $0.9(2)$ & $\underline{1}, 4,[5], 12: \mathrm{i}:-{ }^{\mathrm{H}}$ & $2.4(27)$ & Anatum & $2.1(9)$ & Mbandaka $^{\mathrm{H}}$ & 1 \\
\hline Give & $0.9(2)$ & Agona $^{\mathrm{H}}$ & $2.2(25)$ & Bredeney & $2.1(9)$ & Poona & 1 \\
\hline Indiana & $0.9(2)$ & S. sp. (rough) & $1.2(14)$ & Indiana $^{\mathrm{H}}$ & $2.1(9)$ & Putten & 1 \\
\hline London & $0.9(2)$ & London & $1.1(12)$ & Newport $^{\mathrm{H}}$ & $2.1(9)$ & Senftenberg & 1 \\
\hline Ohio & $0.9(2)$ & Bardo & $0.9(10)$ & Saintpaul $^{\mathrm{H}}$ & $1.9(8)$ & Typhimurium $^{\mathrm{H}}$ & 1 \\
\hline other & $4.0(9)$ & other & $7.5(86)$ & other & $30.5(130)$ & other & 0 \\
\hline
\end{tabular}

H - Top-10 Salmonella serovars noted in humans according to the National Public Health Institute (28)

Table 3. Distribution of Salmonella serovars by food items

\begin{tabular}{|c|c|c|c|c|c|c|c|c|}
\hline \multicolumn{9}{|c|}{ Food sample type (number of isolates) } \\
\hline Serovar & $\begin{array}{c}\text { Food } \\
\text { processing } \\
\text { plant }\end{array}$ & Broiler meat & $\begin{array}{l}\text { Poultry meat } \\
\text { and poultry } \\
\text { meat } \\
\text { products } \\
\text { (unspecified) }\end{array}$ & $\begin{array}{l}\text { Pork and } \\
\text { pork } \\
\text { products }\end{array}$ & Turkey meat & $\begin{array}{c}\text { Meat } \\
\text { (other, } \\
\text { mixed, } \\
\text { unspecified) }\end{array}$ & $\begin{array}{l}\text { Beef and } \\
\text { beef } \\
\text { products }\end{array}$ & $\begin{array}{l}\text { Others and } \\
\text { unspecified }\end{array}$ \\
\hline & $(\mathrm{n}=175)$ & $(\mathrm{n}=482)$ & $(\mathrm{n}=175)$ & $(\mathrm{n}=140)$ & $(\mathrm{n}=98)$ & $(n=33)$ & $(\mathrm{n}=26)$ & $(\mathrm{n}=12)$ \\
\hline Infantis & 37 & 172 & 35 & 12 & 3 & 7 & 1 & 0 \\
\hline Enteritidis & 26 & 100 & 45 & 11 & 2 & 6 & 6 & 5 \\
\hline Indiana & 11 & 96 & 13 & 3 & 0 & 0 & 0 & 0 \\
\hline Newport & 18 & 41 & 28 & 3 & 16 & 3 & 1 & 2 \\
\hline Typhimurium & 12 & 7 & 12 & 32 & 9 & 4 & 6 & 0 \\
\hline Kentucky & 14 & 5 & 3 & 0 & 33 & 0 & 0 & 0 \\
\hline Saintpaul & 10 & 2 & 2 & 3 & 15 & 0 & 2 & 0 \\
\hline Virchow & 3 & 18 & 4 & 3 & 0 & 4 & 0 & 0 \\
\hline Derby & 4 & 0 & 4 & 21 & 1 & 1 & 0 & 0 \\
\hline Mbandaka & 5 & 11 & 10 & 4 & 0 & 0 & 0 & 0 \\
\hline$\underline{1,4,[5], 12: i:-}$ & 5 & 1 & 0 & 15 & 1 & 2 & 3 & 0 \\
\hline Agona & 6 & 4 & 5 & 2 & 6 & 1 & 1 & 0 \\
\hline S.sp. (rough) & 4 & 1 & 7 & 2 & 0 & 0 & 0 & 0 \\
\hline London & 4 & 0 & 0 & 6 & 0 & 1 & 1 & 0 \\
\hline Bardo & 4 & 4 & 2 & 0 & 0 & 0 & 0 & 0 \\
\hline other & 12 & 20 & 5 & 23 & 12 & 4 & 5 & 5 \\
\hline
\end{tabular}


Table 4. Distribution of Salmonella serovars by feed items

\begin{tabular}{|c|c|c|c|c|c|c|c|c|}
\hline \multicolumn{9}{|c|}{ Feedingstuff sample type (number of isolates) } \\
\hline \multirow[t]{2}{*}{ Serovar } & $\begin{array}{c}\text { Feed } \\
\text { production } \\
\text { plant } \\
\text { environment }\end{array}$ & $\begin{array}{c}\text { Plant feed } \\
\text { materials }\end{array}$ & $\begin{array}{c}\text { Animal feed } \\
\text { materials }\end{array}$ & Pet feed & $\begin{array}{l}\text { Compound } \\
\text { feed for } \\
\text { poultry }\end{array}$ & $\begin{array}{l}\text { Compound } \\
\text { feed for } \\
\text { swine }\end{array}$ & $\begin{array}{l}\text { Compound } \\
\text { feed for } \\
\text { ruminants }\end{array}$ & $\begin{array}{l}\text { Others and } \\
\text { unspecified }\end{array}$ \\
\hline & $(\mathrm{n}=97)$ & $(\mathrm{n}=91)$ & $(\mathrm{n}=60)$ & $(\mathrm{n}=57)$ & $(\mathrm{n}=38)$ & $(\mathrm{n}=18)$ & $(\mathrm{n}=17)$ & $(\mathrm{n}=48)$ \\
\hline Mbandaka & 9 & 18 & 0 & 1 & 5 & 2 & 5 & 6 \\
\hline Infantis & 6 & 4 & 13 & 8 & 2 & 0 & 0 & 5 \\
\hline Agona & 4 & 14 & 3 & 2 & 4 & 3 & 2 & 2 \\
\hline Derby & 5 & 4 & 10 & 6 & 0 & 1 & 0 & 2 \\
\hline Senftenberg & 3 & 16 & 2 & 0 & 2 & 1 & 1 & 1 \\
\hline Enteritidis & 1 & 2 & 0 & 3 & 5 & 2 & 3 & 6 \\
\hline Typhimurium & 1 & 3 & 3 & 7 & 0 & 1 & 0 & 4 \\
\hline Lexington & 8 & 3 & 0 & 0 & 4 & 1 & 0 & 0 \\
\hline Livingstone & 3 & 4 & 3 & 0 & 2 & 0 & 2 & 0 \\
\hline $4: \mathrm{d}:-$ & 4 & 0 & 3 & 2 & 0 & 0 & 0 & 0 \\
\hline Anatum & 3 & 0 & 2 & 1 & 1 & 0 & 2 & 0 \\
\hline Bredeney & 2 & 1 & 6 & 0 & 0 & 0 & 0 & 0 \\
\hline Indiana & 0 & 0 & 0 & 4 & 1 & 1 & 0 & 3 \\
\hline Newport & 1 & 1 & 0 & 2 & 0 & 0 & 0 & 5 \\
\hline Saintpaul & 0 & 0 & 0 & 6 & 0 & 0 & 0 & 2 \\
\hline other & 47 & 21 & 15 & 15 & 12 & 6 & 2 & 12 \\
\hline
\end{tabular}

Diversity of serovar pattern in turkey isolates $(\mathrm{D}=0.887)$ was higher than in those recovered from geese $(\mathrm{D}=0.736)$, ducks $(\mathrm{D}=0.772)$, or swine $(\mathrm{D}=0.724)$. The most commonly observed serovars in turkeys were $S$. Kentucky (22.4\%), S. Newport (16.0\%), $S$. Saintpaul (13.2\%), and $S$. Typhimurium (9.1\%).

The same four serovars, but at different frequencies, were observed among isolates from geese and ducks. In geese $S$. Typhimurium (38.1\%) and $S$. Enteritidis $(33.1 \%)$ prevailed, but in ducks both serovars occurred in the opposite order $(S$. Enteritidis at $42.9 \%$ followed by $S$. Typhimurium with $17.7 \%$ ). The occurrence of $S$. Indiana was noted more often in ducks $(8.4 \%)$ than in geese $(6.3 \%)$.

Monophasic $S$. Typhimurium was the predominant serovar in pigs $(47.8 \%)$. High contributions of $S$. Derby $(19.6 \%)$ and $S$. Typhimurium (8.9\%) were observed. Other serovars were rarely noted, with percentages ranging from $0.9 \%$ to $4.5 \%$.

During 2010-2015 only few isolates from cattle were available $(S$. Typhimurium $\mathrm{n}=2$, monophasic $S$. Typhimurium $\mathrm{n}=5, S$. Dublin $\mathrm{n}=3, S$. Enteritidis $\mathrm{n}=1)$.

The most frequent serovars found among isolates from food of animal origin were in decreasing order: $S$. Infantis $(23.4 \%)$ and $S$. Enteritidis (17.6\%) followed by $S$. Indiana $(10.8 \%), S$. Newport $(9.8 \%)$, and $S$. Typhimurium (7.2\%) (Table 2). The first three serovars were also the most often recovered from broiler meat samples, whereas $S$. Typhimurium was most common in pork and pork meat products (Table 3 ).

Among 73 serovars from feedingstuffs, there was no visibly predominant serovar, but $S$. Mbandaka $(10.8 \%), S$. Infantis $(8.9 \%)$ and $S$. Agona $(8.0 \%)$ were relatively often recovered. $S$. Infantis, $S$. Typhimurium, and $S$. Derby were often noted in pet feed (Table 4). That source of isolation along with fertilisers showed the highest variability $(\mathrm{D}>0.9)$ of the serovars observed during the study.

Thirty-one isolates from fertilisers covered 15 serovars. Noteworthy is the fact that identified serovars like $S$. Infantis, $S$. Enteritidis, $S$. Virchow, $S$. Newport, $S$. Typhimurium, monophasic $S$. Typhimurium, $S$. Derby, $S$. Kentucky, and $S$. Mbandaka were also the most commonly found in animals, foods, and humans.

\section{Discussion}

Data collection on the occurrence of Salmonella is a crucial element in control of the pathogen in animals and provides a possibility to evaluate the efficiency of national Salmonella control programmes. Products of animal origin are considered to be the main source of Salmonella for humans. Salmonella-contaminated feed, a possible vector of new Salmonella serovars to animals, via food of animal origin, may finally affect consumers' health. Each year Salmonella serovars different than those targeted in national Salmonella control programmes cause several human illnesses. Comparison of top serovars noted in the USA and EU clearly demonstrates geographical differences in Salmonella epidemiology $(7,11)$. Monitoring of the distribution of Salmonella serovars from various sources is relevant for the detection of national and global Salmonella outbreaks and supports good insight into current epidemiological status $(11,30)$.

As far as we know, this study is one of the most extensive presentations on the occurrence of Salmonella serovars from a national perspective and provides detailed data on serovar distribution, wide spectrum of serovars, and a variety of Salmonella sources.

Many serovars noted along the food chain in Poland were also responsible for human infections $(27,28)$. 
Finding the same Salmonella serovars in humans, animals, food of animal origin, and feedingstuffs might indicate their epidemiological linkages. As shown in the study, some currently spotted tendencies might result in serious epidemiological consequences.

In the present study $S$. Enteritidis, which is responsible for the greatest proportion of human salmonellosis cases in Poland (78.6\% in 2014), along with $S$. Infantis and $S$. Mbandaka $(27,28)$, represented also serovars most frequently observed in animals. It was particularly demonstrated in poultry, where in the case of hens and geese dominating serovars proved to be $S$. Enteritidis, $S$. Infantis, and $S$. Mbandaka, but in ducks - $S$. Enteritidis and $S$. Infantis. Similar distribution pattern of these three serovars in broilers, laying hens, and breeding flocks of Gallus gallus (data not shown) might result from farm environment contamination and vertical transmission of the infection inside the breeding flocks. Salmonella serovars found in food of animal origin reflect the distribution of serovars among livestock. $S$. Enteritidis and $S$. Infantis, as the most prevalent in food of animal origin, represent a good example as we noted a significant increase in $S$. Infantis presence in food compared to our previous study (from $12.2 \%$ up to $23.4 \%$ ), whereas, at the same time $S$. Enteritidis decreased from $26.3 \%$ down to $17.6 \%$ (17). It can be assumed that this shift in predominant serovars is the effect of Salmonella control programmes in poultry aiming at limited number of serovars. Broiler and unspecified poultry meat seem to be the main source of these two serovars for humans in Poland and the same situation is observed across the EU $(10,11)$. Franco et al. (14) reported spread of multidrug-resistant $S$. Infantis causing infections in humans in Italy between 2011 and 2014, and the outbreak clone strain was associated with broilers and broiler meat. In our study all three poultryassociated serovars were noted in feedingstuffs: poultry feed $-S$. Enteritidis and $S$. Mbandaka, feed materials and pet feed $-S$. Infantis. This finding is a cause for concern and it indicates the role of feedingstuffs as a source of Salmonella transmission to humans. It is worth emphasising that contaminated feeds may affect consumer health in a direct way - by Salmonella infected pet feed and not only via infected animals. In 2012, documented outbreak of human salmonellosis caused by $S$. Infantis transmitted from "Dry Dog Food" was reported in the United States and Canada (5). Feedassociated outbreak noted in Austria in 2010 showed the indirect way of Salmonella transfer to humans. Eggs obtained from flocks fed $S$. Mbandaka-contaminated feed were the main cause of human illness (1). Epidemiological success and public health consequences of $S$. Mbandaka ST413 spread in Poland were addressed elsewhere (19). Currently ongoing eggrelated multi-country $S$. Enteritidis outbreak was traced back to a packing centre and multiple laying hen farms in Poland (8).

Similarly to above-mentioned serovars, $S$. Virchow, listed among the main causes of human infections, was also associated mostly with hens and broiler meat (11,
28). Occurrence of this serovar in other animal species and feedingstuffs was low. That is consistent with previous findings showing that $S$. Virchow is rarely isolated from sources other than humans and chickens (29).

$S$. Typhimurium, the second most prevalent serovar among the human salmonellosis cases in Poland (6.2\% in 2014) and across the EU (15.8\% in 2015) $(11,28)$, occurred very often in hens, geese, ducks, turkeys, and pigs in Poland. Notifiable decline of $S$. Typhimurium incidents in hens (from 5.6\% to 3.5\%) and in foods (from $14.3 \%$ to $7.2 \%$ ) was observed during this study compared to 2005-2010 (17). We assume that this reduction might result from implementation of national Salmonella control programmes in poultry, similarly to a decrease in $S$. Enteritidis infection. $S$. Typhimurium was the most frequently recovered from pork and poultry meat, the same as it was observed in food-associated Salmonella outbreaks across the EU and in the USA (11, 20, 22).

Interestingly, in comparison to our previous study, the number of $S$. Typhimurium pig isolates decreased from $27.4 \%$ to $8.9 \%$ and it was replaced by monophasic $S$. Typhimurium (17). Similarly to Poland, monophasic strains of $S$. Typhimurium (Salmonella $1,4,[5], 12: \mathrm{i}:-$ and S. 1,4,12:i:-) represented a significant number of pig isolates in Spain, Malta, the United Kingdom, and Italy $(10,11)$. Monophasic $S$. Typhimurium - the worldwide emerging pathogen - has been occurring in Poland since $2008(16,33)$. In 2015, it was the third most frequently reported serovar in pigs and the second serovar recovered from pork across the EU (11). In comparison to other European countries, where monophasic $S$. Typhimurium was the third most important serovar associated with human salmonellosis, epidemiological significance of this serovar in humans seems to be limited in Poland (11). In 2014 it took the $9^{\text {th }}$ place on the list of the top human serovars (28).

$S$. Derby, another serovar associated with pork production worldwide, consistently persists among serovars responsible for human salmonellosis $(11,28)$. Seven percent increase in the number of this serovar in pigs was noted compared to the previous period (17). We found only few $S$. Derby isolates coming from other animal species (data not presented). $S$. Derby and $S$. Typhimurium were recovered in pet feed. This is another proof that feed might be the possible direct or indirect source of Salmonella infections.

Serovars $S$. Newport, $S$. Kentucky, and $S$. Saintpaul were found most frequently among isolates from turkeys and turkey meat. This serovar pattern was different than those observed in other poultry species in Poland. The rationale for that could be an import of breeding material for turkey fattening flocks. We noted a change in Salmonella serovars distribution in turkeys in comparison to the previous years when $S$. Saintpaul, $S$. Typhimurium, and $S$. Newport were the most frequent serovars (17). The epidemic spread of multiresistant $S$. Kentucky in turkey flocks in Poland has been observed since 2010 (32). 
$S$. Kentucky and $S$. Newport were listed among the top ten serovars in human salmonellosis across the EU, causing $0.7 \%$ and $1.0 \%$ of all reported cases in 2015 (11). Turkey associated Salmonella outbreaks were repeatedly reported. Previously described epidemic spread of $S$. Saintpaul in a cluster of EU countries (34) presumably continues since it caused a multi-country outbreak in 2012. This led $S$. Saintpaul to become the fifth most commonly reported serovar in 2012 in humans across the EU (9). During the study, a similar turkeyrelated outbreak affecting hundreds of people in several countries was caused by $S$. Stanley (24).

It is noteworthy that in Poland, unlike in other European countries, $S$. Indiana and $S$. Agona persist among top serovars responsible for human salmonellosis. In 2014, these two serovars caused $0.37 \%$ and $0.83 \%$ of all human Salmonella cases respectively (28). Still there were some reports on outbreaks associated with these serovars in other countries, for example a large $S$. Agona outbreak in England in 2013 (13), caused by contaminated food of plant origin, namely curry leaves. Most of our $S$. Indiana and $S$. Agona isolates were associated with poultry. We noted an increase in the number of $S$. Indiana originating from geese and ducks (17). Similar situation was observed in Great Britain where $S$. Indiana became the most prevalent serovar in ducks during 2012 and 2013 (2). The number of $S$. Indiana isolates from food increased dramatically compared to our previous study (17). Interestingly, we found $S$. Indiana occurring almost as frequently as $S$. Enteritidis in broiler meat samples (Table 3). High percentage of this serovar in broiler meat compared to its presence in hens may suggest crosscontamination during slaughter or the fact that the serovar is not targeted in control programmes. It is disturbing that there are several reports on $S$. Indiana carrying quinolones resistance genes widespread in chickens and ducks in China $(3,25)$.

The presented data show a variety of possible Salmonella sources. We indicate that geese and ducks might also be relevant source of epidemiologically important Salmonella serovars to humans and more attention should be paid to this infection route. The epidemiological situation in bovine salmonellosis in Poland has not been part of this study. Nevertheless, the importance of serovars found in cattle and beef indicates the need for further investigation. The varieties of serovars found in feeds confirm their role as Salmonella introduction route to animal flocks (18). The most common Salmonella serovars found in feedingstuffs were also noted among serovars isolated from animals and humans. A large diversity of serovars isolated from feeds and feed products could have been associated with the import of contaminated feeds and raw feed materials coming from different geographic regions of the world (18).

Since the number of studied Salmonella isolates obtained from fertilisers was small, it is difficult to draw a substantive conclusion. However, top nine Salmonella serovars associated with human and animal infections were noted, including $S$. Enteritidis, multiresistant $S$. Kentucky, and monophasic variant of $S$. Typhimurium. This implicates the role of animals in Salmonella circulation in the environment and also points that fertilisers, similarly to feedingstuffs, might be a threat to humans. It also indicates that fertilisers can play an important role in the spread of Salmonella by contaminated food of plant origin.

Our study focused on Salmonella serovars along the food chain, but we should bear in mind other reservoirs of Salmonella such as wildlife or pet animals. In terms of Salmonella infections, reptile pets, whose popularity continues to grow, are of particular importance (35).

Salmonella serovars vary in their pathogenic potential and have different entryways into human population. That is why talking about Salmonella epidemiology is a significant simplification. In order to gain a better perspective, further molecular typing studies, including whole genome sequencing (WGS), pulsed field gel electrophoresis (PFGE), multilocus sequence typing (MLST), antimicrobial resistance testing, and identification of specific resistance mechanisms are needed to explore specifics of spread of particular Salmonella serovars along the food chain in Poland.

Monitoring of Salmonella occurrence and definite serovar identification are essential for determination of infection sources and reduction of salmonellosis in humans (17). The observed continuous decrease in infection rate during the study period presumably results from Salmonella control programmes in poultry across the EU, targeting $S$. Enteritidis, $S$. Typhimurium, $S$. Hadar, $S$. Infantis, and $S$. Virchow in Gallus gallus breeding flocks, and $S$. Enteritidis and $S$. Typhimurium in other poultry populations covered by the programmes $(11,20)$. However, decrease in occurrence of one serovar is often associated with an increase in the other serovars that may also cause foodborne outbreaks. This suggests that the applied control measures are not equally efficient against all Salmonella serovars and that more attention should be paid to different sources of infection. Therefore, Salmonella control programmes should be updated to target other epidemiologically important serovars. It is essential to serotype a number of isolates from different sources for an insight on emerging serovars and trends of Salmonella infections. This could increase the value of epidemiological data and result in prompt actions leading to efficient protection of consumers' health.

Conflict of Interests Statement: The authors declare that there is no conflict of interests regarding the publication of this article.

Financial Disclosure Statement: The research was funded by KNOW (Leading National Research Centre) Scientific Consortium "Healthy Animal - Safe Food".

Animal Rights Statement: None required. 


\section{References}

1. Allerberger F.: Molecular typing in public health laboratories: from an academic indulgence to an infection control imperative. J Prev Med Public Health 2012, 45, 1-7.

2. Animal Health and Veterinary Laboratories Agency and Animal and Plant Health Agency: Salmonella in livestock production in Great Britain, 2013. Animal Health and Veterinary Laboratories Agency ISBN 1899513 426: England, Scotland, and Wales, 2014.

3. Bai L., Zhao J., Gan X., Wang J., Zhang X., Cui S., Xia S., Hu Y., Yan S., Wang J., Li F., Fanning S., Xu Y.: Emergence and diversity of Salmonella enterica serovar Indiana isolates with concurrent resistance to ciprofloxacin and cefotaxime from patients and food-producing animals in China. Antimicrob Agents Chemother 2016, 60, 3365-3371.

4. Butaye P., Michael G.B., Schwarz S., Barrett T.J., Brisabois A., White D.G.: The clonal spread of multidrug-resistant non-typhi Salmonella serotypes. Microb Infect 2006, 8, 1891-1897.

5. Centers for Disease Control and Prevention: Human Salmonella Infantis infections linked to dry dog food - United States and Canada, 2012. Morb Mortal Wkly Rep 2012, 61, 436.

6. Centers for Disease Control and Prevention: Surveillance for Foodborne Disease Outbreaks United States, 2014: Annual Report 2014, 1-20.

7. Crim S.M., Iwamoto M., Huang J.Y., Griffin P.M., Gilliss D., Cronquist A.B., Cartter M., Tobin-D'Angelo M., Blythe D., Smith K., Lathrop S., Zansky S., Cieslak P.R., Dunn J., Holt K.G., Lance S., Tauxe R., Henao O.L.: Incidence and trends of infection with pathogens transmitted commonly through food - foodborne diseases active surveillance network. Morb Mortal Wkly Rep 2014, 63, 328-332.

8. European Food Safety Authority; European Centre for Disease Prevention and Control: Multi-country outbreak of Salmonella Enteritidis phage type 8, MLVA type 2-9-7-3-2 and 2-9-6-3-2 infections. EFSA supporting publication 2016:EN-1110, doi:10.2903/sp.efsa.2016.EN-1110.

9. European Food Safety Authority; European Centre for Disease Prevention and Control: The European Union summary report on trends and sources of zoonoses, zoonotic agents and food-borne outbreaks in 2012. EFSA J 2014, 12, 1-312.

10. European Food Safety Authority; European Centre for Disease Prevention and Control: The European Union summary report on trends and sources of zoonoses, zoonotic agents and food-borne outbreaks in 2014. EFSA J 2015, 13, 1-191.

11. European Food Safety Authority; European Centre for Disease Prevention and Control: The European Union summary report on trends and sources of zoonoses, zoonotic agents and food-borne outbreaks in 2015. EFSA J 2016, 14, 1-231.

12. Foley, S.L., Lynne A.M., Nayak R.: Salmonella challenges: prevalence in swine and poultry and potential pathogenicity of such isolates. J Anim Sci 2008, 86, 149-162.

13. Foster K.: Outbreak of Salmonella Agona phage type 40 associated with the Street Spice Festival, Newcastle upon Tyne. Public Health England 2013, (February/March 2013), 1-72.

14. Franco A., Leekitcharoenphon P., Feltrin F., Alba P., Cordaro G., Iurescia M., Tolli R., D'Inca M., Staffolani M., Di Giannatale E., Hendriksen R.S., Battisti A.: Emergence of a clonal lineage of multidrug-resistant ESBL-producing Salmonella Infantis transmitted from broilers and broiler meat to humans in Italy between 2011 and 2014. PLoS One 2015, 10.

15. Grimont P.A.D., Weill F.-X.: Antigenic formulae of the Salmonella serovars. WHO Collaborating Centre for Research on Salmonella, Institute Pasteur, Paris, 2007.

16. Hoszowski A., Samcik I., Lalak A., Skarżyńska M., Wnuk D., Zając M., Wasyl D.: Characterization of monophasic isolates of Salmonella enterica serovar Typhimurium (1,4,[5],12:i:-). Med Weter 2014, 70, 117-121.

17. Hoszowski A., Skarżyńska M., Wasyl D., Zając M., Lalak A., Samcik I., Wnuk D.: Salmonella serovars in animals, food and feed during the years 2005-2010 in Poland. Med Weter 2012, 68, 411-417.

18. Hoszowski A., Wasyl D., Salmonella serovars found in animals and feeding stuffs in 2001 and their antibiotic resistance. Bull. Vet. Inst. Pulawy 2002, 46, 165-178.

19. Hoszowski A., Zając M., Lalak A., Przemyk P., Wasyl D.: Fifteen years of successful spread of Salmonella enterica serovar Mbandaka clone ST413 in Poland and its public health consequences. Ann Agricult Environl Med 2016, 23, 237-241.

20. Hugas M., Beloeil P.: Controlling Salmonella along the food chain in the European Union - progress over the last ten years. Europ Commun Dis Bull 2014, 19, 1-4.

21. Hunter P.R., Gaston M.A.: Numerical index of the discriminatory ability of typing systems: an application of Simpson's index of diversity. J Clin Microbiol 1988, 26, 2465-2466.

22. Jackson B.R., Griffin P.M., Cole D., Walsh K.A., Chai S.J.: Outbreak-associated Salmonella enterica serotypes and food commodities, United States, 1998-2008. Emerg Infect Dis 2013, $19,1239-1244$

23. Jones T.F., Ingram L.A., Cieslak P.R., Vugia D.J., TobinD'Angelo M., Hurd S., Medus C., Cronquist A., Angulo F.J.: Salmonellosis outcomes differ substantially by serotype. J Infect Dis 2008, 198, 109-114.

24. Kinross, P., van Alphen L., Martinez Urtaza J., Struelens M., Takkinen J., Coulombier D., Makela P., Bertrand S., Mattheus W., Schmid D., Kanitz E., Rucker V., Krisztalovics K., Paszti J., Szogyenyi Z., Lancz Z., Rabsch W., Pfefferkorn B., Hiller P., Mooijman K., Gossner C.: Multidisciplinary investigation of a multicountry outbreak of Salmonella Stanley infections associated with turkey meat in the European Union, August 2011 to January 2013. Europ Commun Dis Bull 2014, 19, 1-10.

25. Lu Y., Zhao H., Zhou X., Wang J., Liu T., Beier R. C., Hou X.: Characterization of quinolone resistance in Salmonella enterica serovar Indiana from chickens in China. Poult Sci 2015, 94, 454-460.

26. PN-EN ISO 6570:2003: Microbiology of food and animal feeding stuffs - Horizontal method for the detection of Salmonella spp. 2002, 1-27.

27. PZH and GIS: Infectious diseases and poisonings in Poland in 2013. National Institute of Public Health - PZH / Chief Sanitary Inspectorate - GIS, Warsaw, 2014, 1-174.

28. PZH and GIS: Infectious diseases and poisonings in Poland in 2014. National Institute of Public Health - PZH / Chief Sanitary Inspectorate - GIS, Warsaw, 2015, 1-166.

29. Salisbury A., Leeming G., Nikolaou G., Kipar A., Wigley P.: Salmonella Virchow infection of the chicken elicits cellular and humoral systemic and mucosal responses, but limited protection to homologous or heterologous re-challenge. Front Vet Sci 2014, $1,1-13$.

30. Vo A.T., van Duijkeren E., Fluit A.C., Heck M.E., Verbruggen A., Maas H.M., Gaastra W.: Distribution of Salmonella enterica Serovars from humans, livestock and meat in Vietnam and the dominance of Salmonella Typhimurium Phage Type 90. Vet Microbiol 2006, 113, 153-158.

31. Wagenaar J.A., Hendriksen R.S., Carrique-Mas J.: Practical considerations of surveillance of Salmonella serovars other than Enteritidis and Typhimurium. Rev Sci Techn 2013, 32, 509-519.

32. Wasyl D., Hoszowski A.: First isolation of ESBL-producing Salmonella and emergence of multiresistant Salmonella Kentucky in turkey in Poland. Food Res Internatl 2012, 45, 958-961.

33. Wasyl D., Hoszowski A.: Occurrence and characterization of monophasic Salmonella enterica serovar Typhimurium $(1,4,[5], 12: i:-)$ of non-human origin in Poland. Foodborne Pathog Dis 2012, 9, 1037-1043.

34. Wasyl D., Zając M., Brown D.J., Kuronen H., Van Der Zwaluw K., Hoszowski A.: Molecular epidemiology of Salmonella enterica serovar Saintpaul isolated from animals, food, and humans in 12 European countries. Bull Vet Inst Pulawy 2012, 56, 459-466.

35. Zając M., Wasyl D., Hoszowski A., Le Hello S., Szulowski K.: Genetic lineages of Salmonella enterica serovar Kentucky spreading in pet reptiles. Vet Microbiol 2013, 166, 686-689. 